\title{
Peripheral Vitrectomy Under Air for Primary Rhegmatogenous \\ Retinal Detachment in Pseudophakic Eyes
}

\section{Rodrìguez Maqueda Mariano ${ }^{1,2,3 *}$, Gonzalez Lozano Juan Manuel ${ }^{1}$ and Seva Silva Norberto ${ }^{1}$}

${ }^{1}$ Hospital Universitario Virgen del Rocìo, Sevilla, Spain

${ }^{2}$ Hospital Quiròn Sagrado Corazòn, Sevilla, Spain

${ }^{3}$ Clìnica Miranza Oculsur, Càdiz, Spain

*Corresponding Author: Rodrìguez Maqueda Mariano, Hospital Universitario

Virgen del Rocìo and Hospital Quiròn Sagrado Corazòn and Clìnica Miranza

Oculsur, Càdiz, Spain.
Received: February 15, 2020

Published: February 24, 2020

(C) All rights are reserved by Rodrìguez

Maqueda Mariano., et al.

\begin{abstract}
Purpose: To evaluate safety, efficacy and surgical technique of peripheral vitrectomy under air for primary rhegmatogenous retinal detachment in pseudophakic patients.

Patients and Methods: 47 consecutives retrospective observational cases were enrolled. All the patients had undergone a peripheral vitrectomy under air without scleral indentation by a single surgeon. At the end of the surgery a $360^{\circ}$ peripheral photocoagulation was performed. No scleral buckling was done. Outcomes included were: peripheral iatrogenic retinal breaks during peripheral vitrectomy, surgical technique (specific settings for this approach) and retinal reattachment.

Results: Only in one case there was an intraoperative iatrogenic break. Higher intraocular pressure, fewer cuts and higher vacuum were found the most efficient settings for peripheral vitrectomy under air respect to fluid. All the cases were reattached after the first surgery with a follow up of 12 months.

Conclusions: Performing peripheral vitrectomy under air in pseudophakic retinal detachment is a safe and efficient technique with some benefits but it requires an understanding of the fluidic dynamics and a change of configuration from the usual settings for peripheral vitrectomy under fluid.
\end{abstract}

Keywords: Retinal; Vacuum; Peripheral Vitrectomy

\section{Introduction}

Rhegmatogenous retinal detachment (RRD) requires an extensive vitreous removal. The goal is remove as much peripheral vitreous as possible in a safe way [1]. Peripheral vitrectomy under air increases the field of view and could eliminate the need for scleral indentation, as well as hold the retinal surface while we are close to the vitreous base. However, in pseudophakic eyes small retinal breaks might not be detected under air due to poor contrast and fogging of the posterior capsule [2].
We analize in this text the efficacy and safety of peripheral vitrectomy under air infusion as well as the settings for this technique.

\section{Methods}

This is a cohort study of 47 consecutives retrospective observational cases who underwent peripheral vitrectomy under air infusion for primary rhegmatogenous retinal detachment. All patients had pseudophakic condition previous to retinal detachment. Patients were excluded if they had previous vitreoretinal surgery, 
proliferative vitreoretinopathy, choroidal detachment, giant retinal tear or retinal dialysis, anterior chamber lens implant and subluxated intraocular lens.

The follow up was 12 months.

All the surgeries were carried out by one surgeon at two hospitals. Vitrectomy was performed with 23-gauge instruments. Constellation Vision System (UHS Alcon Constellation; Alcon Laboratories, Inc, Fort Worth, TX) was used for 27 cases and EVA (D.O.R.C. Dutch Ophthalmic Research Center International) was employed for 20 cases. All the surgeries were performed using contact wideangle viewing system and without scleral indentation.

The settings for peripheral vitrectomy under air for Constellation Vision System were: air infusión at $35 \mathrm{mmHg}$, cut rate 2500 per minute in core mode and vacuum value of $450 \mathrm{mmHg}$; for EVA were: air infusión $30 \mathrm{mmHg}$, cut rate 6000 per minute (real cut rate 12000 per minute due to two-dimensional cutting vitrectome) and vacuum value of 450 .

Peripheral vitreous shaving under air was performed following air-fluid exchange and after drainage of the subretinal fluid. Therefore, retinal reattachment was necessary in order to realize this technique safely_(Video 1).

We employed C3F8 or SF6 gas tamponade and sclerotomies were sutured carefully with partial-thickness 7.0 Vicryl sutures.

Percentage of patients with retinal reattachment after this surgery over 12 months as well as intraoperative retinal tears were analyzed.

\section{Results and Conclusions}

Peripheral vitrectomy under air is a safe and effective technique for shaving peripheral vitreous in pseudophakic patients with retinal detachment $[3,4]$. Usually, the surgeon performs shaving under fluid and assisted with scleral indentation.

In those cases where contact wide-angle viewing systems are used, the sum of indentation and correct lens placement are able to be compromised, making both difficult; in a same way, for some manoeuvers might be a lack of space for that reason [5].

In our cohort study all patients achieved retinal reattachment and only one suffered an intraoperative tear (probably due to "learning curve" of the technique). In fact, the main possible complication of this procedure is producing a retinal break while shaving closely at the vitreous base.

Anyway, in all procedures we performed prophylactic $360^{\circ}$ laser treatment for prevention of retinal re-detachment because of an unnoticed tear.

Vitrectomy under air increase by 20 degrees the visualization of peripheral retina, allowing pars plana visualization without the need for scleral indentation. Thereby the need or dependence of an experienced assistant for indentation decreases, particularly if we are using a contact wide-angle viewing system. On the other hand, peripheral vitreous is pushed against the reattached retina, decreasing iatrogenic tears by avoiding retinal movements under fluid when vitrectome is close to retina and retina is detached.

The fluid dynamics for this technique is different from the conventional one under fluid: it is necessary to keep the port open longer for increasing the duty-cycle (with different settings according each vitrectomy platform), the vacuum can't be low, and the air infusion must be slightly higher for prevent sudden hypotony. Likewise, the vitrectome tip must be fully inserted in the peripheral vitreous before cutting and then we have to pull away it a bit while we begin to cut and aspirate this vitreous in a safe way.

In conclusion, in our cases retinal re attachment has proven to be excellent performing a peripheral vitrectomy under air and not inferior to previously described papers using conventional peripheral vitrectomy under fluid. The complication rate has comparable results from published works, being a safe procedure $[3,4]$.

\section{Bibliography}

1. Charles S., et al. "Vitreous Microsurgery. 5th ed". Philadelphia, PA: Lippincott Williams and Wilkins (2010).

2. Voleti VB., et al. "Vitrectomy under air". Retina 32.9 (2012): 1981-1982.

3. Erdogan G., et al. "Comparing peripheral vitrectomy under air and fluid infusion for primary rhegmatogenous retinal detachment”. Retina 36.7 (2016): 1281-1284.

4. Altan T., et al. "Results of peripheral vitrectomy under air in rhegmatogenous retinal detachment". Ophthalmic Surgery, Lasers and Imaging Retina 48.1 (2017): 51-54. 
5. Mateo C and Burés-Jelstrup A. "Contact versus noncontact wide-field viewing systems: Why Not Have the Best of Both Worlds?" Retina 38.4 (2018): 854-856.

\section{Assets from publication with us}

- Prompt Acknowledgement after receiving the article

- Thorough Double blinded peer review

- Rapid Publication

- Issue of Publication Certificate

- High visibility of your Published work

Website: $\underline{w w w}$.actascientific.com/

Submit Article: www.actascientific.com/submission.php

Email us: editor@actascientific.com

Contact us: +919182824667 